UDC 34.06

LBC 67.75

\title{
MEDIATION TECHNOLOGIES OF RESOLVING MATRIMONIAL CONFLICTS ${ }^{1}$
}

\author{
Roman G. Melnichenko \\ Volgograd State University, Volgograd, Russian Federation
}

Introduction: based on the concept of technological mediation procedures, the article provides an overview of the application of various mediation techniques to resolve matrimonial conflicts. Using the experience in the legal and psychological science, the author sets the goal to explore the mediation technologies in the resolution of matrimonial conflicts. The task is to study the algorithms of particular mediation technologies. Methods: the methodological framework for the research is the combination of the following methods of scientific knowledge: the comparative scientific method, the methods of systematicity and analysis. Results: the author offers a classification of the technologies for solving matrimonial conflicts: facilitatorship, echo technique, caucus, externalization, deconstruction, rewriting, and the triangle of fate. Conclusions: the technological approach to mediation activities for resolving matrimonial conflicts is promising both from the standpoint of the science, in which the identification and fixation of mediation technologies take place and the law enforcement practice where these technologies can be applied.

Key words: mediation, technology, matrimonial conflict, echo technique, caucus, externalization, deconstruction, the triangle of fate, rewriting.

УДК 34.06

ББК 67.75

\section{МЕДИАТИВНЫЕ ТЕХНОЛОГИИ РАЗРЕШЕНИЯ СЕМЕЙНЫХ КОНФЛИКТОВ ${ }^{1}$}

\section{Роман Григорьевич Мельниченко}

Волгоградский государственный университет, г. Волгоград, Российская Федерация

Введение: основываясь на представлении о технологичности медиационных процедур, в статье дается обзор возможностей применения различных медиационных приемов к разрешению семейных конфликтов. Используя опыт юридической и психологической наук, нами поставлена цель исследовать технологии в медиационной деятельности при разрешении семейных конфликтов. В качестве задачи взято исследование алгоритмов отдельных медиационных технологий. Методы: методологическую основу исследования составляет совокупность следующих методов научного познания: сравнительно-научный метод, метод системности и метод анализа. Результаты: автором предлагается классификация технологий по разрешению семейных конфликтов: фасилитаторство, эхо-техника, кокус, экстернализация, деконструкция, пересочинение, треугольник судьбы. Выводы: технологический подход к медиационной деятельности по разрешению семейных конфликтов является весьма перспективным как с позиции науки, в рамках которой происходит идентификация и фиксация медиационных технологий, так и правоприменительной практики, где эти технологии могут применяться.

Ключевые слова: медиация, технология, семейный конфликт, эхо-техника, кокус, экстернализация, деконструкция, треугольник судьбы, пересочинение.

\section{Введение}

Семейные конфликты - это идентифицированное противоречие интересов между людьми, объединенными родственными или супружескими связями. Перед тем, как пере- ходить непосредственно к технологиям разрешения семейных конфликтов, необходимо определиться с субъектами этих конфликтов, так как от этого будет зависеть то, какая технология будет применена, а так же как именно она будет применена. Можно выделить 
следующие пары субъектов, в отношении которых возникают семейные конфликты:

- супруг - супруга;

- ребенок - мать;

- ребенок - отец;

- ребенок - родители.

В свою очередь можно выделить и ряд медиационных технологий, например, эхо-технику и кокус [5, с. 123], а также ряд других, которые можно использовать при разрешении семейных конфликтов. Рассмотрим во3можности применения медиационных технологий к такой конфликтующей паре, как супруг - супруга.

Конфликт в той или иной форме присущ супружеским отношениям, но нетерпимой точки он достигает, как правило, при разводе супругов. Авторы отмечают: «Чаще всего семейная медиация нужна при расставании или разводе пары для того, чтобы помочь ей сохранить свой статус родителей и отделить совместное выполнение парой своих родительских обязанностей от эмоций, связанных с прекращением их взаимоотношений в качестве партнеров. Медиация помогает родителям сфокусироваться на индивидуальных потребностях и чувствах их детей и выработать схему, по которой будут строиться их отношения с детьми в дальнейшем» [3, с. 42]. Действительно, в медиационной практике нам не встречались примеры «безразводных» семейных споров. Рассмотрим возможности ряда медиационных приемов применительно к семейным конфликтам: фасилитаторство, экстернализация, деконструкция, пересочинение, эхо-техника, треугольник судьбы и кокус.

\section{Прием фасилитатора}

Существует несколько базовых подходов медиатора к своей деятельности, от которых зависят те приемы, которые он применяет в ходе процедуры медиации: трансформативный, понимания, нарративный и оценочный.

Трансформативная медиация (transformative approach) - следование за клиентом. Задача медиатора при трансформативном подходе - наладить коммуникацию между участниками медиационного процесса.

Медиация, основанная на понимании (understanding-based approach), - «пойми и от- вечай за себя». Задача медиатора здесь - повысить осознанность участников медиационного процесса.

Нарративная медиация (narrative approach) - конфликт понимается как история (рассказ). Задача медиатора - при помощи участников переписать эту историю из истории конфликта в историю сотрудничества.

Оценочная медиация (evaluative approach) - «предложить варианты». Медиатор влияет на процесс медиации, оценивая происходящее, и оказывает влияние на результат диалога, при необходимости предлагая свои варианты разрешения конфликта.

В зависимости от роли медиатора в медиационной процедуревыделяют два «крайных» подхода: фасилитатор и модератор. Фасилитатор (англ. facilitator, от лат. facilis - «легкий, удобный») - это человек, обеспечивающий успешную групповую коммуникацию. В случае, когда медиатор выбирает роль фасилитатора, он целенаправленно не ставит перед собой задачи решить конфликт определенным образом. Модератор это управляющий процедурой. Если медиатор выберет модерацию, он берет на себя роль ведущего, знающего какую цель должны достичь участники медиационного процесса.

В вышеприведенном определении задач семейной медиации, данном О.В. Костиной, Е.А. Овсяниковой, Н.И. Долженко и И.В. Савельевой, видно, что они придерживаются «модераторского» подхода, так как сами определяют задачу медиационной сессии как построение отношений между разведенными родителями по поводу воспитания детей. Однако нам этот подход представляется весьма опасным. Ведь при разрешении семейных конфликтов у их участников могут быть разные задачи: от примирения до полного разрыва и оставления друг-друга в покое. На каком основании медиатор сам ставит задачу перед конфликтующими сторонами?

Технология фасилитатора в разрешении семейных конфликтов в формате супруг - супруга состоит в сознательном отрешении медиатора от постановки перед собой, а значит и перед своими доверителями какой-либо задачи. Медиатор создает условия для разговора, в ходе которого конфликтующие супруги сами приходят к постановке задачи с последующим ее разрешением. 


\section{Нарративные приемы в семейной медиации}

Три медиационные техники для разрешения семейных конфликтов между супругами взяты из арсенала нарративной медиации. Нарративная медиация - это подход к медиации, основанный на предположениях о том, что люди живут и действуют в моделях, описаниях реальности, созданных во взаимодействии людей и институционализированных, и ни одно из этих описаний не является «истинным».

Для применения нарративной техники необходимо уяснить саму идею нарратива. Ее основа заключается в предположении о том, что человек осознает свою жизнь как совокупность небольших историй, которые он для себя вербализирует в качестве небольших рассказов (нарративов). Например, рассказ о том, как человек в субботу утром испек блины, а затем пригласил всех членов семьи за стол. В этом своем рассказе человек «зашифровал» не всю реальность, которая лишь частично получила свое описание в рассказе. Он включил в рассказ лишь то, что показалось для него важным на момент составления нарратива. После сочинения нарратива человек размышляет о той ситуации, по поводу которой составлен рассказ, исключительно в рамках этого нарратива.

Конфликт, согласно нарративной медиации, - это рассказ. Если конфликт происходит между людьми - это, как минимум, два рассказа. Приемы нарративной медиации могут быть применимы, если медиатор понимает подобную разметку.

В ходе семейной медиации можно использовать три нарративных приема: экстернализацию, деконструкцию и пересочинение.

Выведение (экстернализация) нарратива - это процедура отстранения рассказчика от своего нарратива, то есть автор нарратива должен выйти из своего рассказа, перейти из роли участника рассказа в роль внешнего наблюдателя. Медиатор может, например, предложить супругу: «Расскажите, пожалуйста, о своей ситуации так, как будто вы наблюдаете ее со стороны» или «Представьте, что все, о чем вы рассказываете, происходит на экране кинотеатра». Экстернализация - это прием, направленный на дистанцирование супругов от травмирующего нарратива, который содержит рассказ о конфликте. Экстернализация проходит в несколько этапов: погружение в нарратив, выведение нарратива, персонализация нарратива.

Результатом экстернализации может стать снижение эмоционального фона супругов, что повлечет за собой возможность поиска «на холодную голову» приемлемых для обеих сторон возможностей разрешения семейного конфликта.

Деконструкция - это прием нарративной медиации, который заключается в идентификации, размягчении и, возможно, изменении убеждений, лежащих в основе нарратива, содержащего рассказ о супружеском конфликте. Деконструкции подвергаются сами собой разумеющиеся убеждения (пресуппозиции), лежащие в основе описаний мира клиента, которые находятся в конфликте, а также «ощущение себя вправе» вести себя определенным образом, которое следует из этих убеждений. Для получения компетенции работы с таким приемом, как деконструкция, целесообразно провести определенную процедуру.

Первый этап процедуры состоит из погружения, выведения, поименования, наделения дееспособностью и оценки. На этапе оценки уже можно начать работу по проверке ценности того убеждения, на котором выстроен нарратив. Подобное убеждение можно назвать пресуппозицией. Буквально пресуппозиция это предположение. Это подразумевающееся убеждение, которое не вербализируется в нарративе, но на нем нарратив построен. Например, можно предположить, что нарратив «Ему на меня наплевать» основан на пресуппозиции о том, что супруги обязаны проявлять эмоции при беседах друг с другом. И потому следующий этап процедуры деконструкции это расследование.

Расследование - это поиск и вербализация той пресуппозиции, которая лежит в основе нарратива. Это довольно сложная задача для медиатора. Дело здесь в нескольких факторах, построенных на том, что у людей нет практики выявления пресуппозиций. Первый фактор заключается в том, что пресуппозиция в речи не проговаривается, то есть в обычной речи ее услышать невозможно. Второй 
фактор состоит в явлении сокрытия нарратива. Супруг чувствует, что выявление пресуппозиции может повлечь ее изменение, что в свою очередь вызовет изменение позиции клиента. Именно поэтому клиент неосознанно старается скрыть свои пресуппозиции. В ходе выполнения этой части упражнения основная возникающая трудность - это именно попытка супруга скрыть свои пресуппозиции. Перечислим основные «техники сокрытия пресуппозиций»:

- агрессия - у клиента после выхода медиатора на пресуппозицию резко повышается эмоциональный фон, он становится агрессивным, переходит в наступление на медиатора. В свою очередь, медиатор после идентификации подобного явления может использовать его как признак выхода на пресуппозицию клиента;

- замыкание - клиент замолкает или прямо отказывается дальше обсуждать этот вопрос;

- ложные мишени - клиент старается завуалировать свои пресуппозиции псевдопозициями.

Сама конструкция пресуппозиций хорошо коррелируется с основным тезисом гарвардской школы медиации - это соотношение явлений «позиция» и «цель» (кейс мать - дочери апельсин). Выявить пресуппозицию значит обнаружить цель, которую преследуют в конфликте противоборствующие стороны, и которая завуалирована их позициями.

Следующий этап процедуры деконструкции - это стадия оценки пресуппозиции. После обнаружения пресуппозиций необходимо добиться того, чтобы ее носитель проговорил роль этой пресуппозиции в конфликте. Если эта роль негативная, индивид сам должен прийти к этому выводу. Только тогда можно приступать непосредственно к деконструкции. Пресуппозиция - это очень стойкое психологическое образование. Оно имеет глубокие корни, как правило, не только в жизни клиента, но и в жизни его предков, да и самой культуры, в которой он существует. Было бы наивно надеяться на то, что медиатор «в одно касание» деконструирует (развалит) пресуппозицию. Можно лишь попытаться ее расшатать (размягчить). Следующий этап деконструкции это Расшатывание.
Расшатать пресуппозицию значит подвергнуть убеждения (пресуппозиции) сомнению. Например, на предыдущем этапе оценки пресуппозиции клиент увидел, что именно его пресуппозиция является камнем преткновения конфликта. Медиатор может расшатать пресуппозицию, используя, например, все те же приемы нарративной медиации. Приведем пример из уже рассмотренного нами нарратива «Ему на меня наплевать». Клиентом было вербализировано, что в основании этого нарратива лежит его пресуппозиция о том, что «Супруг обязан проявлять эмоции при беседе с другим супругом». Клиенту предлагается составить пресуппозицию-антоним. Клиент, например, предложит следующую пресуппозицию-антоним: «Супруг обязан спокойно выслушать проблему, чтобы принять взвешенное безэмоциональное решение». Затем клиенту предлагается временно принять пресуппозицию-антоним в качестве своей личной пресуппозиции и ответить на ряд вопросов медиатоpa, например: «Почему не всегда хорошо ярко проявлять свои эмоции?», «можно ли решить проблему, находясь в возбужденном эмоциональном состоянии?».

В идеале прием деконструкции может привести к исчезновению конфликта между супругами. Так, если даже одна спорящая сторона поймет, что в основании конфликта лежит ее пресуппозиция, а сама эта пресуппозиция эту сторону не устраивает, то в случае изменения или отказа от этой пресуппозиции это приведет к прекращению самого конфликта. Но это в идеале. В любом случае, размягчение обеих пресуппозиций спорящих сторон сделает более реальной работу по сближению, а в дальнейшем - к созданию синтезированной единой пресуппозиции.

Пересочинение - это еще один прием нарративной медиации, который можно применить при разрешении семейного конфликта между супругами. Цель этого приема - изменение истории конфликта (нарратива, в котором содержится конфликт). Препятствием для подобного приема является существующая в нашем социуме пресуппозиция, которую можно сформулировать так: «Историю изменить нельзя! Ее можно переврать!». Нарративная же медиация стоит на предположении о том, что, по крайней мере, личная история - это история 
субъективная, и она в лучшем случае содержит в себе лишь небольшую часть истории, которую можно условно обозначить как история объективная. С позиции нарративной медиации, объективная история - это принятая за истинную большинством чья-либо субъективная история (ученых, политиков).

Личная история в лексиконе нарративной медиации - это доминирующая история, то есть актуальный нарратив индивида о какомлибо событии. Актуальный, то есть существующий сейчас. Прием пересочинения - это работа с доминирующей историей. Дело в том, что из доминирующей истории о конфликте «выпадают» и остаются незамеченными эпизоды взаимного уважения, поддержки и сотрудничества в настоящее время конфликтующих супругов. Это какие-то события, которые с точки зрения доминирующей конфликтной истории умалчиваются (например, история консолидации супругов в какой-либо ситуации). Медиатор, осуществляя совместно с супругами пересочинение, помогает связать отдельные исключения из доминирующей истории в осмысленную последовательность, в «противосюжет», который можно противопоставить истории о конфликте.

\section{Эхо-техника в семейной медиации}

Эхо-техника - это прием активного слушания. Спорящие супруги, как правило, или молчат, или говорят, но при этом не слышат друг друга. Эхо-техника поможет медиатору разрешить данную проблему.

Побуждение супруга к высказыванию: некоторые супруги могут испытывать трудности в высказывании своей позиции, например, из-за страха перед другим супругом, боязни проговориться и тем самым ухудшить свое положение, косноязычии и т. п. При помощи повторения части фразы супруга медиатор побуждает сторону продолжать и активизировать говорение. Например, медиатор говорит запнувшемуся на полуслове доверителю: «Значит, вы перестали понимать друг друга»?

Прояснение понимания супругами другдруга: медиатор повторяет с вопросительной интонацией непонятное ему в речи супруга место. Например: «Что значит “он меня игнорирует"»?
Удержание эмоционального фона между супругами - достаточно часто встающая перед медиатором задача. Чтобы успокоить «разбушевавшуюся» сторону, медиатор повторяет спокойным тоном услышанные в речи говорящего эмоционально нейтрально окрашенные фразы, например: «пришел к выводу», «успокоился», «понял».

\section{Треугольник судьбы в семейной медиации}

Понятие «треугольник судьбы» (треугольник Карпмана) ввел в научный, а затем и психолого-терапевтический оборот Стивен Карпман [7]. В медиации данная конструкция рассматривается в разделе «групповых конфликтов». Различают два подхода к групповому конфликту. Дуалистический подход основан на утверждении о том, что сколько бы интересантов не участвовало в конфликте, они относятся к одной или другой конфликтующей стороне.

Трехсторонний подход основан на утверждении о том, что в групповых конфликтах три стороны. Корни данного подхода находятся в традиции трансактного анализа Э. Берна, согласно которой при коммуникации люди выбирают какую-либо социальную роль [1]. Применительно к треугольнику судьбы, при групповом конфликте его участник выбирает одну из трех ролей: агрессора, жертвы или спасителя. Применительно к семейным конфликтам традиционна следующая ситуация. Супруга берет на себя роль жертвы: «Он меня игнорирует!». Супруг - роль агрессора: «Да отстанет она от меня когда-нибудь!», а, например, мама супруги всецело отдается роли спасителя: «Да брось ты его, такого черствого!».

Рекомендуемый прием, основанный на концепции «треугольник судьбы», - это рефлексия своей роли в семейном конфликте. Медиатор рассказывает спорящим сторонам о «треугольнике судьбы» и предлагает им выявить, какую роль каждый из них выбрал в данном конфликте и кто в этом конфликте является третьим? Как правило, после рефлексии стороны остаются недовольными той ролью, которую они играют в конфликте, а это первый шаг выхода из ситуации «треугольника судьбы», а значит и выхода из конфликта. 


\section{Кокус (caucus) в семейной медиации}

В медиации под кокусом понимается медиационная техника, которая заключается в индивидуальной беседе с одной из сторон. Технически кокус происходит следующим образом. Медиатор идентифицирует необходимость в проведении индивидуальной беседы с одним из супругов. Он объявляет об этом спорящим сторонам и удаляется с одной из них в отдельное помещение вне зоны слышимости другой стороны. Рассмотрим функции кокуса применительно к семейной медиации.

1. Понижение эмоционального фона супругов. Разводя супругов по разным комнатам, медиатор способствует их успокоению. Например, в боксе этой функции служит команда «брэк».

2. Предупреждение супруга. Например, медиатор может указать одному из супругов, что он ведет себя так, как будто хочет использовать медиацию для наказания другого супруга. Если сказать об этом в присутствии другой стороны, это может способствовать прекращению коммуникации.

\section{Результаты}

Произведена классификация технологий медиационной деятельности в семейном конфликте. Составлен алгоритм пяти медиационных технологий семейной медиации: фасилитаторство, эхо-техника, нарративные приемы (экстернализация, деконструкция и пересочинение), треугольник судьбы и кокус.

\section{Заключение}

Представленные медиационные технологии при разрешении семейных споров не являются исчерпывающими. Особенностью их применения является особых характер семейных конфликтов.

\section{ПРИМЕЧАНИЕ}

1 Исследование выполнено при финансовой поддержке РГНФ и Администрации Волгоградской области в рамках проекта проведения научных исследований («Медиативные технологии снижения социальной конфликтности в деятельности долж- ностных лиц органов местного самоуправления Волгоградской области»), проект №16-13-34020.

\section{СПИСОК ЛИТЕРАТУРЫ}

1. Берн, Э. Игры, в которые играют люди. Люди, которые играют в игры / Э. Берн. - М. : АСТ, 1998. $-397 \mathrm{c}$.

2. Геворкян, Т. В. Медиация как один из альтернативных способов разрешения споров и ее влияние на правовую культуру общества / Т. В. Геворкян // Вестник Волгоградского государственного университета. Серия 5, Юриспруденция. - 2013. № 1 (18). - С. 155-158.

3. Костина, О. В. Семейная медиация как одно из ведущих направлений государственной семейной политики / О. В. Костина, Е. А. Овсяникова, Н. И. Долженко, И. В. Савельева // Наука и образование: хозяйство и экономика; предпринимательство; право и управление. - 2014. - № 10 (53). - С. 42-46.

4. Мельниченко, Р. Г. Медиация : учебное пособие для бакалавров / Р. Г. Мельниченко. - М. : Дашков и К, 2014. - 192 с.

5. Мельниченко, Р. Г. Технологичность медиационной деятельности / Р. Г. Мельниченко // Правовая парадигма. - 2017. - Т. 16. № 2. - С. 123-128.

6. Перекрестов, В. Н. Признание вины как условие медиации в уголовном процессе // Вестник Волгоградского государственного университета. Серия 5, Юриспруденция. - 2011. - № 1 (14). - С. 205-209.

7. Стюарт, Й. Жизненный сценарий: как мы пишем историю своей жизни / Й. Стюарт, В. Джойнс // Психологическая библиотека Киевского Фонда содействия развитию психической культуры. - Электрон. текстовые дан. - Режим доступа: http://psylib. org.ua/books/stewj01/index.htm. - Загл. с экрана.

8. Трофимов, Я. В. Современное развитие медиации в Российской Федерации: правовые или неправовые принципы составляют ее основу? / Я. В. Трофимов // Вестник Волгоградского государственного университета. Серия 5, Юриспруденция. - 2013. - № 1 (18). - С. 76-80.

\section{REFERENCES}

1. Bern E. Igry, v kotorye igrayut lyudi. Lyudi, kotorye igrayut v igry [The Games Played by People. The People Who Play Games]. Moscow, AST Publ., 1998.397 p.

2. Gevorkyan T.V. Mediatsiya kak odin iz alternativnykh sposobov razresheniya sporov i ee vliyanie na pravovuyu kulturu obschestva [Mediation as One of the Alternative Ways to Resolve Disputes and Its Impact on the Legal Culture of Society]. Vestnik 
Volgogradskogo gosudarstvennogo universiteta. Seriya 5, Yurisprudentsiya [Science Journal of Volgograd State University. Jurisprudence], 2013, no. 1 (18), pp. 155-158.

3. Kostina O.V., Ovsyanikova E.A., Dolzhenko N.I., Savelyeva I.V. Semeynaya mediatsiya kak odno iz vedushchikh napravleniy gosudarstvennoy semeynoy politiki [Family Mediation as One of the Leading Areas of the State Family Policy]. Nauka $i$ obrazovanie: khozyaystvo $i$ ekonomika; predprinimatelstvo; pravo i upravlenie, 2014, no. 10 (53), pp. $42-46$.

4. Melnichenko R.G. Mediatsiya [Mediation]. Moscow, Dashkov i K Publ., 2014. 192 p.

5. Melnichenko R.G. Tekhnologichnost mediatsionnoy deyatelnosti [Technological Nature of Mediation Activity]. Pravovaya paradigm [Legal Concept], 2017, vol. 16, no. 2, pp. 123-128.

6. Perekrestov V.N. Priznanie viny kak uslovie mediatsii v ugolovnom protsesse [Admission of Guilt as a Condition of Mediation in Criminal Proceedings].
Vestnik Volgogradskogo gosudarstvennogo universiteta. Seriya 5, Yurisprudentsiya [Science Journal of Volgograd State University. Jurisprudence], 2011, no. 1 (14), pp. 205-209.

7. Stewart J., Jones V. Zhiznennyy stsenariy: kak my pishem istoriyu svoey zhizni [Life Scenario: How We Write Our Life Story]. Psikhologicheskaya biblioteka Kievskogo Fonda codeystviya razvitiyu psikhicheskoy kultury [Psychological Library of the Kyiv Foundation for the Promotion of the Development of Mental Culture]. URL: http://psylib. org.ua/books/stewj01/index.htm.

8. Trofimov Ya.V. Sovremennoe razvitie mediatsii v Rossiyskoy Federatsii: pravovye ili nepravovye printsipy sostavlyayut ee osnovu? [The Current Development of Mediation in the Russian Federation: Legal or Non-Legal Principles Form Its Basis?]. Vestnik Volgogradskogo gosudarstvennogo universiteta. Seriya 5, Yurisprudentsiya [Science Journal of Volgograd State University. Jurisprudence], 2013, no. 1 (18), pp. 76-80.

\section{Information about the Author}

Roman G. Melnichenko, Candidate of Juridical Sciences, Associate Professor, Leading Researcher, Institute of Law, Volgograd State University, Prosp. Universitetsky, 100, 400062 Volgograd, Russian Federation, romanmelnichenko@yandex.ru, melnichenko@volsu.ru.

\section{Информация об авторе}

Роман Григорьевич Мельниченко, кандидат юридических наук, доцент, ведущий научный сотрудник института права, Волгоградский государственный университет, просп. Университетский, 100, 400062 г. Волгоград, Российская Федерация, romanmelnichenko@yandex.ru, melnichenko@volsu.ru. 